\title{
EMBRACING NEW VISUALISATION TOOLS IN EDUCATION: HOW THE LEARNING EXPERIENCE OF DIGITAL SKETCHING INFLUENCES ITS USE IN DESIGN PRACTICE
}

\author{
Zhang, Wenwen (1); \\ Ranscombe, Charlie (2) \\ 1: University of Canterbury; \\ 2: Swinburne University of Technology
}

\begin{abstract}
Numerous visualisation tools based on digital and cross-reality (XR) platforms are emerging in industrial design. They offer new possibilities and promising advantages to the designers but also raise challenges for design education. This study investigates the learning experience of emerging tools in education and its influences on tool-use behaviours and attitudes in design practice. Digital sketching is selected for the case study as the emerging tool compared to more established tools (e.g., traditional sketching and CAD). Semi-structured interviews were conducted with 12 practising designers to compare their learning experience of digital sketching versus traditional sketching and CAD modelling in formal education. Results indicate that designers' learning experience in education can have an influence on not only their skill sets but also attitudes towards engaging with emerging visualisation tools as they progress in their careers. The study suggests that embracing emerging design visualisation tools in education now is essential for helping our future designers be more resilient and flexible with tool selection and use in their future design practice.
\end{abstract}

Keywords: Industrial design, Design education, Case study, Emerging tools, Digital sketching

\author{
Contact: \\ Zhang, Wenwen \\ University of Canterbury \\ School of Product Design \\ New Zealand \\ wendy.zhang@canterbury.ac.nz
}

Cite this article: Zhang, W., Ranscombe, C. (2021) 'Embracing New Visualisation Tools in Education: How the Learning Experience of Digital Sketching Influences its Use in Design Practice', in Proceedings of the International Conference on Engineering Design (ICED21), Gothenburg, Sweden, 16-20 August 2021. DOI:10.1017/pds.2021.135 


\section{INTRODUCTION}

In industrial design, the selection and use of design visualisation tools have significant influences on the effectiveness of the design process and the design outcome (Self et al., 2009; Ranscombe et al., 2020). The development of relevant technologies offers numerous visualisation tools to industrial designers, which opens up new possibilities for design processes and workflows. Such tools include digital sketching, digital sculpturing, and other emerging visualisation tools based on digital and crossreality (XR) platforms. Despite the potential advantages of such tools, observations in the industry suggest their application in design practice is relatively limited compared to more established visualisation tools (e.g., traditional sketching, 3D CAD modelling, digital rendering). In other words, the usage of emerging visualisation tools in design practice is not necessarily in line with their advanced capabilities, which indicates potentially untapped resources in the community.

This study investigates this phenomenon from an education perspective. The majority of formal industrial design education still focuses on training predominantly more established tools. Hence, this study seeks to explore if and how the learning experience of emerging visualisation tools in formal education influences their use in practice. Digital sketching is selected as the target tool for the case study, and comparisons are drawn between digital sketching and the more established traditional sketching and CAD modelling. Digital sketching has been employed in the industrial design field for more than 25 years (Kolli and Hennessey, 1993), and it was very much considered as an emerging visualisation tool in higher education 5-10 years ago (Aldoy and Evans, 2011). Hence the timeline of the growth of digital sketching in industrial design makes examining the influences of its learning experience with practising designers possible.

\section{DESIGN VISUALISATION TOOLS}

There are numerous design visualisation tools employed by industrial designers in practice to capture, externalise, communicate, and present their design work (Goldschmidt, 2004; Kim et al., 2013; Lutters et al., 2014). These design visualisation tools nowadays can vary from traditional (pen-on-paper) sketching to immersive drawing and modelling in virtual reality (VR). For this study, design visualisation tools are defined as tools to assist non-physical 2D or 3D manifestation of design concepts. In other words, design tools for 2D design visualisation with both traditional and digital media are included, e.g., traditional and digital sketching. 3D design tools in virtual space are also considered as design visualisation tools (e.g., CAD modelling) distinct from prototyping tools for generating physical manifestations of the design. As stated in the introduction, digital sketching is the example of a relatively underused emerging tool (Evans et al., 2015; Berg and Vance, 2017) on which this study focuses.

In this study, digital sketching refers to the type of design visualisation tools that are based on digital graphic tablets with pen-like input. Other platforms (e.g., XR) than digital tablets are not discussed in this study, which will be covered in future research. The emergence of digital sketching has relied on technological advances in both hardware and software. In terms of hardware for digital sketching, graphics tablets were first created in the early 1960s and have been advanced significantly over the past decades with technology developments. Designers can employ different digital tablets for sketching, including for example, smartphones, iPads, and Microsoft Surface Pro series. There are also more diverse methods used for displaying the graphic outputs of the tablets, which makes the use of this emerging tool easier and easier. For example, digital tablets with embedded touch- and displayscreens nowadays can support intuitive hand-eye coordination and simulate natural pen-paper working environment. Perhaps most significant, these graphic tablets that can support digital sketching are getting more and more affordable. According to an investigation on top e-commerce websites (e.g., Amazon, eBay), drawing tablets with a display screen are around 400 US dollars and without a built-in screen are usually under 100 US dollars.

For software, most of the professional graphic tablets are compatible with mainstream graphic software products on computers including Adobe Photoshop, Adobe Illustrator, Autodesk Sketchbook Pro, as well as software products offered by the digital tablet suppliers. For digital sketching, there are also applications on smart tablets that make the tool more portable and thus more convenient. Likewise, popular applications for digital sketching are offering mobile versions of the software above (e.g., Adobe Photoshop Sketch, Concepts, Procreate). 
With the hardware and software capabilities, it seems that digital sketching can offer new possibilities of the design processes and workflows to industrial designers. For example, Marx (2000) proposes that an almost infinite number of independent layers in digital sketching that "can be moved and manipulated without affecting other layers, and can be edited in several ways, always preserving the ability to change back to a previous version". Thus, the layers feature can also help the completion or annotation of design representations (Eiliat and Pusca, 2013). Other features such as colour panels, visual effects, filters, templates, scale, connectivity to digital 3D environment, etc. may further assist designers' thinking process (Ranscombe et al., 2019) and give "a highly realistic appearance" (Eissen and Steur, 2007) and better-quality design result (Ibrahim and Rahimian, 2010). In summary, digital sketching offers an extended tool kit compared to traditional sketching (Aldoy and Evans, 2011).

However, studies show that the use of digital sketching is still relatively limited (Camba et al., 2018). Similarly, we see that courses or training of digital sketching and other emerging visualisation tools (e.g., XR sketching or modelling tools) in formal design education are limited in duration compared to more established traditional tools (e.g., traditional sketching, CAD modelling) (Zhang et al., 2019). Hence, this study aims to investigate how learning experience influences use behaviours and attitudes towards digital sketching in comparison with traditional sketching and CAD modelling. The investigation is conducted as follows.

\section{METHOD}

Semi-structured interviews are conducted as the basis to investigate the influences of learning experience on patterns of tool use. Influences, in this study, are defined through attitudes or concerns the designer hold when explaining their use of tools during interviews. Interviews were conducted with 12 practising industrial/product designers from 3 design firms regarding their learning experience of digital sketching, traditional sketching, and CAD in formal education as well as designers' current tool use behaviours and preferences. As discussed above, digital sketching is chosen as the emerging visualisation tool for the case study, and the comparable established visualisation tools are traditional sketching and CAD modelling.

\subsection{Interview participants}

Conducting interviews is a traditional research method to gain the opinions, attitudes and perceptions of a certain group of people (Hanington and Martin, 2012). Semi-structured interviews with 12 practising designers, as in Table 1, were adopted in this case study to provide an in-depth understanding of their learning experience of the chosen tools in formal education and their current use and attitudes towards them. The interview participants were coded as P1-P12. 8 out of the 12 participants have more than 5 years of design experience and play different roles at their workplaces. They were recruited because one of the focuses in this study is to examine the potential influences of the learning experience in education on tool use behaviours and mindsets. 4 junior designers (less than 5 years of working experience) were also recruited for a more comprehensive data sample. The 12 participants all have a similar level of educational background (a bachelor's degree in industrial/product design) which helps control for influence of this variable on findings.

Table 1. Interview participants

\begin{tabular}{|l|l|l|l|l|}
\hline Participants & Design firm & Role & Work experience & Educational background \\
\hline P 1 & A & Project Leader & 5-10 years & Bachelor's Degree \\
P 2 & A & Senior Designer & 5-10 years & Bachelor's Degree \\
P 3 & B & Manager & 5-10 years & Bachelor's Degree \\
P 4 & B & Senior Designer & 5-10 years & Bachelor's Degree \\
P 5 & C & Manager & 5-10 years & Bachelor's Degree \\
P 6 & C & Project Leader & 5-10 years & Bachelor's Degree \\
P 7 & C & Project Leader & 5-10 years & Bachelor's Degree \\
P 8 & D & Designer & 5-10 years & Bachelor's Degree \\
P 9 & C & Designer & 1-4 years & Bachelor's Degree \\
P 10 & C & Designer & 1-4 years & Bachelor's Degree \\
P 11 & C & Designer & 1-4 years & Bachelor's Degree \\
P 12 & C & Designer & $1-4$ years & Bachelor's Degree \\
\hline
\end{tabular}




\subsection{Data collection}

The interview session with each participant took approximately 1 hour. The interviews were conducted with the designers face-to-face in an individual manner where audio recordings and transcripts were produced and collected. Nine interview questions (shown in Table 2) are designed as a guideline to gather experiences and attitudes about the learning and use of digital sketching, traditional sketching, and CAD from the interview participants. The participants were free to discuss and express their thoughts on the listed questions and other spontaneous questions based on their responses. This approach is consistent with methods of Crilly (2015) and Self et al. (2009) in comparable studies.

Table 2. Interview questions

\begin{tabular}{|l|l|}
\hline No. & Question \\
\hline Q 1 & How long have you been working as an industrial/product designer? \\
\hline Q 2 & How long have you been in your current design team and what is your role? \\
\hline Q 3 & What do you think about digital sketching? \\
\hline Q 4 & Can you briefly introduce your general design process? \\
\hline Q 5 & Which design tools do you use during the early/middle/later design phases? And why? \\
\hline Q 6 & $\begin{array}{l}\text { How long do you usually spend on using traditional sketching in a design project? } \\
\text { And what about digital sketching and CAD modelling? }\end{array}$ \\
\hline Q 7 & $\begin{array}{l}\text { Did you learn how to use traditional sketching, digital sketching, and CAD modelling } \\
\text { in your formal design education? If so, how long did you spend on learning and } \\
\text { practising them? }\end{array}$ \\
\hline Q 8 & $\begin{array}{l}\text { How is your experience of learning traditional sketching, digital sketching, and CAD } \\
\text { modelling? }\end{array}$ \\
\hline Q 9 & $\begin{array}{l}\text { What tool and representation do you prefer to visualise your ideas during the design } \\
\text { process? And why? }\end{array}$ \\
\hline
\end{tabular}

\subsection{The Design Tool Characteristics (DTCs) framework and data analysis}

The data analysis in this study follows a coding scheme using the inductive coding method (Thomas, 2006) illustrated in Figure 1. The coding scheme is derived from the Design Tool Characteristics (DTCs) framework (Zhang et al., 2019). This framework is selected as the basis for our coding scheme for two reasons. Firstly, the framework provides a generalised view of design tools hence making it possible to draw comparisons between different visualisation tools (Zhang et al., 2019). More importantly for our study, the framework includes a number of user-related characteristics that are used to code and hence describe the designer's attitudes or concerns while using tools.

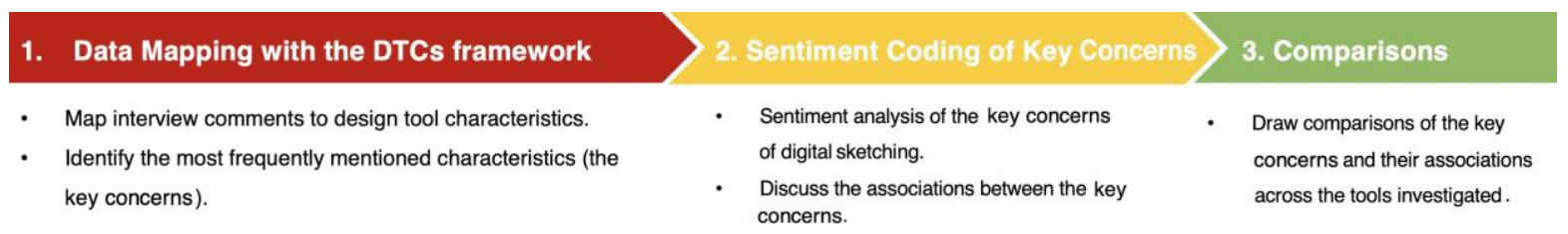

Figure 1. Illustration of the coding process of the interview data

The raw interview data from the audio recordings were first transcribed by the researchers to text files. Then each interview comment was indexed with respect to the tool described (digital sketching, traditional sketching or CAD). Then the interview comments of digital sketching are coded based on characteristics, and the frequency of the characteristics cited forms the basis for identifying attitudes or concerns (Step 1 in Figure 1). The sentiment associated with each is then coded to understand designers' learning experience of digital sketching and explaining patterns of their tool-use behaviours and attitudes (Step 2 in Figure 1). From the different sentiment results of each concern, what motivates and discourages the designers during their learning process of digital sketching can be further discussed. Sentiments related to each concern are coded as either, positive, negative, or mixed. Mixed sentiments are defined as the interview comment shows both positive and negative sides of a tool. 
The coding scheme is also used to explore the associations among the key concerns of the learning experience of digital sketching. The associations are noted where multiple concerns are mentioned together within an interview comment. Associations thus provide a more multifaceted understanding of how multiple concerns together can influence the learning experience. Finally, the same coding process is applied to the interview data on traditional sketching and CAD then comparisons of the learning experience of the three tools are drawn (Step 3 in Figure 1). The key concerns of digital sketching are used as the basis to compare the learning experience and current tool-use attitudes of emerging digital sketching versus the more established visualisation tools.

\section{RESULTS}

Results of the case study are presented as follows. First, an overview of participants' current use of the tools versus their formal training in the three tools is given. Next, the results of coding responses describing use patterns of digital sketching in terms of attitudes and concerns are provided. This is then contrasted with patterns of use of traditional sketching and CAD.

\subsection{The learning and usage of digital sketching}

Figure 2 provides an overview of the current use of the three tools among the participants (2a) contrasted with whether and to what extent they were taught to use these tools in formal education (2b). Immediately, it is clear that the usage of digital sketching among the interview participants is lower than both traditional sketching and CAD modelling. Only half of the participants (6/12) are using digital sketching in their design practice, which is significantly less compared to the use of traditional sketching (12/12) and CAD (11/12). Figure 2 also indicates another interesting pattern that participants' persistence with digital sketching seems to be lower than the other tools. One-third (4/12) had experience of using digital sketching at some point in their practice but have subsequently ceased using it. This situation only happened to one participant with respect to CAD, which was explained by taking on a leadership role in the creative team. None of the participants had completely abandoned using traditional sketching. With respect to training (Figure 2b), the majority of participants (7/12) did not receive any training in digital sketching during their formal education. Cross-referencing against participants' experience shows those receiving no training are the participants with 5-10 years' experience in the industry and hence went through education comparatively long ago. Participants with less professional experience (1- 4 years) had only an introduction of digital sketching for less than one course/unit. Only two of the junior designers had a dedicated course on digital sketching. In comparison, all participants had one or more dedicated course(s) on traditional sketching and CAD modelling during their formal education. Another point to note is the number of participants using or who have used digital sketching is greater than the number receiving formal education. Hence many participants engaged in some level of self-directed learning of the tool during their career.

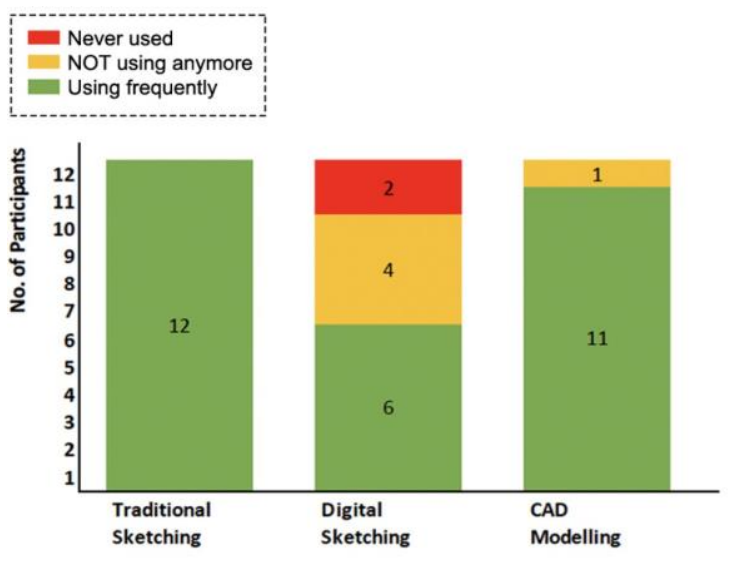

(a)

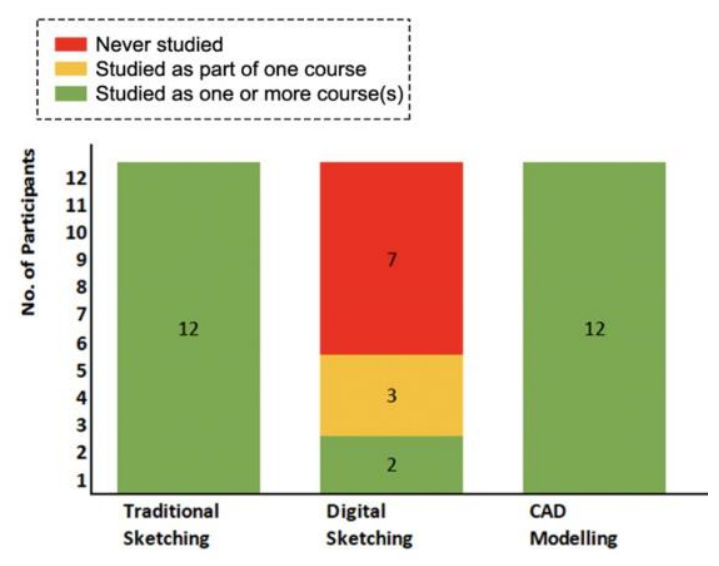

(b)

Figure 2. Participants' usage of the three tools (a) and extent of education (b) 


\subsection{Key concerns of learning digital sketching}

The key concerns cited by participants when commenting on the learning experience of digital sketching in formal education are presented in Figure 3. Note that the sentiments regarding traditional sketching and CAD are included in this figure to provide an overview of the results and further discussions are given in Section 4.3. The most frequently cited concerns are learning cost, user share, expectation, expertise, user accessibility, and user loyalty. As an overview, it is worth noting that participants have primarily negative or mixed sentiments on the majority of these key concerns of digital sketching. A total of 7 out of 10 participants show negative concerns of the time required to learn digital sketching (learning cost); 10 out of 10 participants are not satisfied with the training and learning resources of this tool in education (user share); 3 out of 5 participants are not positive about meeting their expectations of the learning outcome (expectation). Analysis of the data also shows that some of these concerns are connected. Figure 4 figuratively illustrates how these concerns are associated based on how they were cited together, which are discussed below.

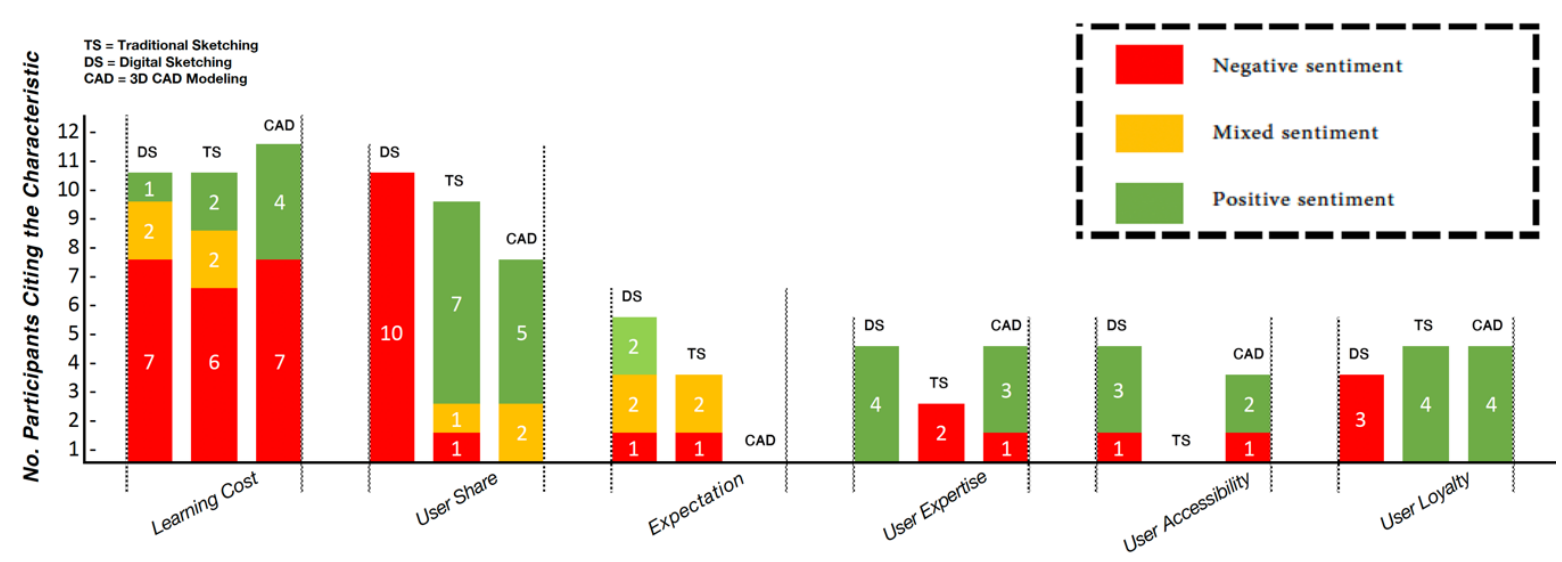

Figure 3. key concerns of the learning experience of digital sketching, traditional sketching, and CAD modelling

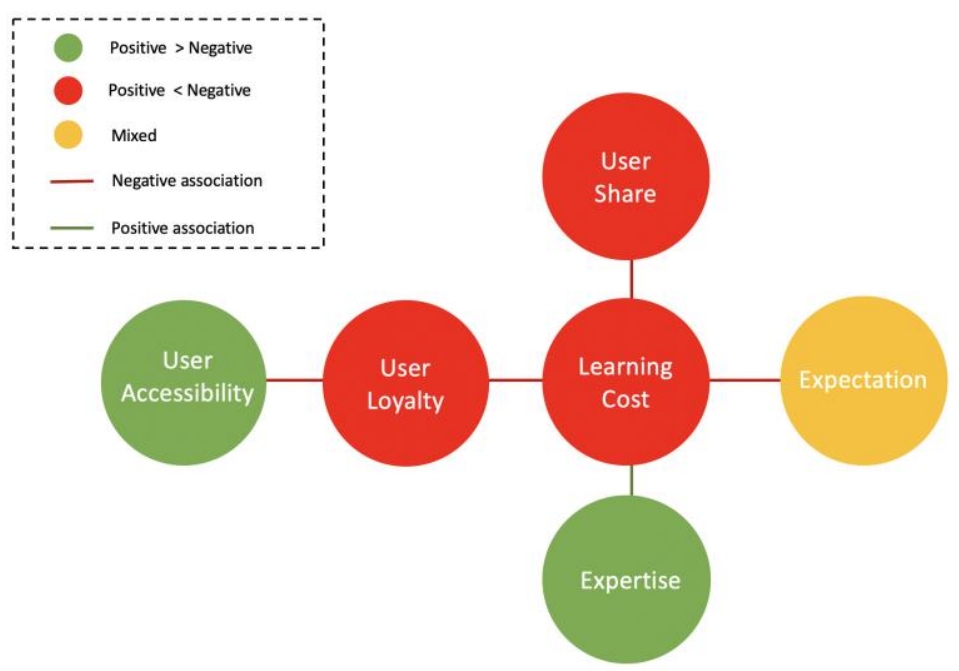

Figure 4. Associations of the key concerns of the learning experience of digital sketching

\section{- $\quad$ Learning cost, user share in education, and expectation}

Learning cost, user share in education and designers' own expectation of the learning outcome are the most frequently cited concerns when participants recall their learning experience of digital sketching. Most participants (10/12) claim that they had insufficient training of digital sketching in their formal education. For example, most of the experienced participants claim that they "did not learn/do any digital sketching at uni" (P4, P5, P8) and "never taught it" (P6). Even for junior participants that graduated within the past 5 years, training of digital sketching was done only "a 3-4 week's component of one unit" (P11) or "had a really short lesson on it during one class of one subject" (P12) rather than a dedicated course. 
Investigating the associations between these concerns suggests that the time required to learn digital sketching is considered high by the designers partially due to the lack of training and learning resources of digital sketching outlined above. A total of 9 out of 12 participants admit that they had to treat digital sketching as a "self-taught" tool and learn it in their "spare time". Others that are not willing to learn digital sketching state that they "just don't have the time (P6)" to do it as practising designers. In addition to time invested, participants also highlight a level of difficulty and even stress experienced while learning the tool. Designers, that did not get sufficient training of digital sketching in education, believe that learning digital sketching is also "tricky", "tougher", "takes time/a while to get there (P8)". This association between perceived time and effort to learn and the lack of training explains the trend highlighted in Section 4.1, that less exposure in education leads to lower levels of use in practice.

Another key concern that is associated with the learning cost and user share is designers' expectation. Specifically, participants usually have a high expectation of the learning outcome, namely, being able to generate high-quality digital sketches quickly. Without sufficient training and guidance of expectations and pace from formal education, many designers feel stressed to achieve high-quality results and get frustrated on their journey to mastering digital sketching. This could well explain the number of participants who had used digital sketching at one point but have since ceased to do so. For example, P2 and P7 express their frustration with learning digital sketching as they have a high expectation of what they "could do" with digital sketching based on examples of digital sketches from the design community seen online.

- $\quad$ Learning cost, expertise, user loyalty, and user accessibility

Expertise, user loyalty, and user accessibility are the other three major concerns cited by multiple participants when commenting on their learning experience of digital sketching. Data suggest designers have less problem with achieving expertise in digital sketching if they have already mastered traditional sketching or relevant digital software. All 4 participants referencing expertise do so with a positive sentiment. Specifically, they indicate positive attitudes towards gaining expertise in digital sketching after the initial period in their learning process. According to the participants, if "you have got the motor skills to actually draw (P2)" from traditional sketching, these skills are "transferable" in digital sketching. In other words, "when you are good at hand sketching you can pick up digital sketching really easily" stated by $\mathrm{P} 4$.

However, user loyalty towards the more established tools also plays a role. Currently, the loyalty towards more established visualisation tools, traditional sketching and CAD modelling, could discourage designers from learning digital sketching. Participants that do not use digital sketching are reluctant to learn due to existing user loyalty towards other tools. For example, P9 states that "I think being exposed to that skill first is the main reason that I'm just preferring hand sketching". Similarly, P3 states "I found that would be more challenging but also because I'm so used to CAD". Finally, 4 out of 12 participants mentioned that having user accessibility to digital sketching devices is essential to ensure a good learning experience of the tool. The current accessibility of digital sketching devices is considered relatively positive in comparison to what it was 5-10 years ago by 3 out of these 4 participants. However, for designers to acquire these devices by themselves is still considered "a bit of investment (P2)". In other words, the interview data validates ensuring digital sketching devices are accessible in education does encourage designers to gain a level of expertise in education which in turn encourages its long-term use in practice.

\subsection{Learning experience of traditional sketching and CAD versus digital sketching}

As illustrated in Figure 3, participants show more positive sentiments towards the same set of concerns regarding their experience of learning traditional sketching and CAD compared to digital sketching. From the data, we see learning cost is still viewed as relatively negative for the more established tools (however less negative than digital sketching) based on the perception that they are time-consuming to learn, practise and master. In other words, the time factor (learning cost) for both emerging and established visualisation tools is mutually high.

As the most established tool among the three, traditional sketching has the least amount of negative feedback regarding the time required to learn the tool (learning cost). Similarly, the negative sentiments coded under expertise in traditional sketching are also primarily about the time required to master it. Designers also feel frustrations in meeting their expectation of the learning outcome of it when learning traditional sketching. However, according to the interview data, traditional sketching 
has the most positive feedback on its user share of learning resources in education. As a result, the greater user share and user accessibility of this tool in formal education seem to ensure that most designers persist with the tool in practice (user loyalty).

Similarly, the learning cost associated with CAD receives more positive sentiments (4 out of 11) compared to the other two tools. A notable sentiment here is that participants claim that the difficulties in learning CAD were only experienced "in the beginning" of the learning process. There is also a positive sentiment towards user share with respect to the learning resources and training of CAD in formal education. Similar to the findings for sketching, we also see that greater exposure to CAD is consistent with greater user loyalty. Finally, we note that no participants flagged the learning expectation of CAD during the interviews. This may occur since CAD deliverable of a design project is quite standard in the industry and can be explained in education clearly and sufficiently based on its user share in education.

\section{DISCUSSION}

\subsection{Influences of the learning experience on tool-use behaviours and mindsets}

According to the literature, digital sketching can assist industrial designers in design practice and offer new possibilities of the design processes and workflows. However, this emerging tool's use and applications among practising designers seem to be relatively limited compared to more established traditional tools. From data, it is clear that the more exposure to a tool in education coincides with more use in practice, likewise, less exposure leads to less use of the tool in practice. In other words, the study suggests that the design visualisation tools learned first and trained more during formal design education are usually more frequently used and preferred in practice. This in itself is not surprising, most design degrees do aim to train students in skills relevant to the industry they are about to enter. What is interesting for the emerging tool is the way that time and effort to gain skills is viewed as much greater than the more established tools, which makes designers less inclined to learn the new tool. Data on positive concerns associated with expertise, expectations and learning cost of the traditional tools (but also negative concerns of digital sketching) suggest there is a threshold of expertise during the learning process.

To be specific, this is the threshold at which point participants gain enough familiarity or expertise to lead to more continuous use of the tools in the long-term. In other words, designers may give up the learning and use of the tool before achieving this expertise threshold, and long-term user loyalty can be expected after passing the threshold. Based on our study, it seems that the expertise threshold for digital sketching is comparable to traditional sketching and CAD. Data suggests that the threshold for digital sketching is not higher, nor does it necessarily take longer to reach. Hence, the primary reason for comparatively low use of digital sketching in practice can be related to a lack of exposure in education (user share and accessibility) meaning the threshold for many participants to continue using digital sketching was not met.

The study also shows a secondary influence of expectation, designers' current expertise, and preference of other established visualisation tools on their use and attitudes towards learning digital sketching. As an emerging tool, digital sketching offers new possibilities for designers to visualise their design ideas. However, it seems that this advantage can lead to high expectations of the learning pace and outcome due to the lack of formal training in education. The study shows that designers tend to compare their learning outcome of digital sketching with highly polished digital sketches on the internet, thus feel stressed and frustrated during the initial learning phase. Hence, these high expectations can further damage the momentum to pass the expertise threshold, and termination of learning during the initial learning phase can be expected. In contrast, P10 had one dedicated unit of digital sketching during their formal design education and have adjusted expectations of using digital sketching as most of the time "just to get the ideas across".

Expectations are of crucial importance considering the rate at which new tools are being developed. It is impossible to foresee and teach every visualisation tool that could emerge during a designer's career while they are at university. Likewise, technological constraints (e.g., hardware performance or cost) may mean that designers have an awareness of tools and expectation of what they can offer for some time before they are able to use/learn them. Data shows more senior designers' view the learning of digital sketching as harder than more junior designers, despite the junior designers also having relatively little training. This may well reflect the senior designers' awareness of the tool for some 
time, further building high expectations. As a consequence, we contend that having guided formal training of digital sketching could help to regulate the expectations, reduce the extra time invested to learn the tool later in the designers' career, and also encourage continued use of the tool in practice.

\subsection{Further work: Embracing emerging design tools using the DTCs framework}

As Lutters et al. (2014) stated, "more and more, designers have to be creative experts, skilful in selecting and employing appropriate tools with the right participants, in the right phase of the project and effective and efficient preparation". Practising designers face the challenge of selecting and using appropriate design visitation tools, including numerous new and emerging design tools. The study shows that the learning experience of visualisation tools can have influences on designers' attitudes towards the tools and potentially other new relevant tools they come across in the future. In other words, formal education can play an important role in preparing designers for this challenge by exposing them to emerging tools in the degree curriculum. However, for educators, providing students with such forward-looking opportunities in formal education can be challenging, especially due to the rapid development of emerging visualisation tools. This study suggests that the DTCs framework, especially the user-related design tool characteristics can also be used to evaluate the learning experience of emerging tools delivered in education. For example, the case study demonstrates the use of the DTCs framework in evaluating and comparing the learning experience of digital sketching, traditional sketching, and CAD. The DTCs framework helped to generalise the learning experience of both emerging tools and more established tools to comparable data. Similarly, more specific evaluation can be conducted for the learning experience of other emerging tools by educators. Hence, using the DTCs framework as a pedagogical tool could make the students' feedback on their learning experience of any emerging tools to more comparable data with the established tools. Hence, strategical improvement of the learning experience can be developed accordingly.

\section{CONCLUSION}

This study aimed to investigate how learning experience influences use behaviours and attitudes towards digital sketching in comparison with traditional sketching and CAD modelling. 12 semistructured interviews with practising designers were conducted to understand the learning experience of the three tools and gather key concerns that motivate their present use of tools. Findings show that embracing emerging visualisation tools in formal industrial design education now is essential to ensure the future designers can adopt and utilise them later in their practice. More importantly, it can influence their attitudes towards emerging visualisation tools for quite some time, including their willingness to continuously learn relevant new tools. As a case study, the result explains how a lack of training on digital sketching (emerging tool) in education between 2010-2015 is associated with designers' current reluctant attitudes towards adopting it in practice in the Asia-Pacific area. At the same time, the study indicates that learning emerging visualisation tools is not necessarily more timeconsuming or frustrating than learning the more established tools, however the perception of difficulty is greater when designers do not experience a tool during their formal education. As such, the study shows that there could be an expertise threshold during the learning process of visualisation tools. Designers/students can build more solid user loyalty towards the tools and also hold reasonable expectations of what they can/should produce as they develop their skills. Hence, we conclude that it is important to provide sufficient exposure of emerging tools in education such that student can reach the threshold of expertise before entering the industry, to in turn maintain a willingness to learn tools further as they evolve and emerge during their career.

Results also provide some ideas on the best approach to new and emerging tools in higher education. The use of DTCs framework highlights the utility of a generalised framework of concerns to create a basis to compare and evaluate the learning experience of design tools. Hence, we conclude that there is value in further exploring how this framework can pedagogically support and evaluate the learning experience of experimental curriculum on emerging design visualisation tools.

Some limitations of the study are noted. For example, the sample size was limited to 12 due to the availability of practising designers. Likewise, the participants are working in the Asia-Pacific area, and designers' educational conditions, tool-use behaviours and attitudes in other areas may vary. The 60minute interview time potentially limits the depth to which use and attitudes towards tools could be discussed. As a final conclusion, the study works as a starting point, which highlights how the learning 
experience of emerging design visualisation tools can influence designers' mindsets and use of tools within their career. Future studies on other emerging visualisation tools such as XR sketching which are just emerging in the industry and how to embrace them in education can be expected as future research.

\section{REFERENCES}

Aldoy, N., and Evans, M. (2011). A review of digital industrial and product design methods in UK higher education. The Design Journal, 14(3), pp. 343-368. https://doi.org/10.2752/175630611X13046972590923

Berg, L. P. and Vance, J. M. (2017), 'Industry use of virtual reality in product design and manufacturing: a survey', Virtual reality, 21(1), pp. 1-17. https://doi.org/10.1007/s10055-016-0293-9

Camba, J. D., Kimbrough, M., \& Kwon, E. (2018). Conceptual product design in digital and traditional sketching environments: a comparative exploratory study. Journal of Design Research, 16(2), pp. 131-154. https://doi.org/10.1504/JDR.2018.092810

Crilly, N. (2015), 'Fixation and creativity in concept development: The attitudes and practices of expert designers', Design Studies, Vol. 38, pp. 54-91. https://doi.org/10.1016/j.destud.2015.01.002

Eiliat, H. and Pusca, D. (2013), 'Teaching and learning experience using digital sketching', in 'Interdisciplinary Engineering Design Education Conference (IEDEC), 2013 3rd', IEEE, pp. 134-138.

Eissen, K. and Steur, R. (2007), Sketching drawing techniques for product, BIS Publishers.

Evans, M., Pei, E., Cheshire, D. and Graham, I. (2015), 'Digital sketching and haptic sketch modelling during product design and development', International journal of product development, 20(3), pp. 239-263. https://doi.org/10.1504/IJPD.2015.069323

Goldschmidt, G. (2004), Design Representation: Private Process, Public Image, pp. 203-217.

Hanington, B. and Martin, B. (2012), Universal methods of design: 100 ways to research complex problems, develop innovative ideas, and design effective solutions, Rockport Publishers.

Ibrahim, R. and Rahimian, F. P. (2010), 'Comparison of cad and manual sketching tools for teaching architectural design', Automation in Construction, 19(8), pp. 978-987.

Kim, S., Jung, S. and Self, J. (2013), 'Investigating design representation: implications for an understanding of design practice', IASDR13 Consilience and Innovation in Design, Korea

Kolli R. and Hennessey J. (1993) Deriving the functional requirements for a concept sketching device: a case study. In: Grechenig T., Tscheligi M. (eds) Human Computer Interaction. VCHCI 1993. Lecture Notes in Computer Science, Vol. 733. Springer, Berlin, Heidelberg. https://doi.org/10.1007/3-540-57312-7_68

Lutters, E., van Houten, F. J. A. M., Bernard, A., Mermoz, E. and Schutte, C. S. L. (2014), 'Tools and techniques for product design', CIRP Annals - Manufacturing Technology, 63(2), pp. 607-630.

Marx, J. (2000), 'A proposal for alternative methods for teaching digital design', Automation in Construction, 9(1), pp. 19-35. https://doi.org/10.1016/S0926-5805(99)00049-7

Ranscombe, C., Bissett-Johnson, K., Zhang, W., Eisenbart, B., \& Lauff, C. (2020). Which visualisation Tools and why? Comparing perceptions of student and practicing designers toward digital sketching. In DS 104: Proceedings of the 22nd International Conference on Engineering and Product Design Education (E\&PDE 2020), VIA Design, VIA University in Herning, Denmark. 10th-11th September 2020. https://doi.org/10.35199/EPDE.2020.30

Ranscombe, C., Zhang, W., Rodda, J. and Mathias, D. (2019), 'Digital sketch modelling: Proposing a hybridvisualisation tool combining affordances of sketching and CAD', Proceedings of the Design Society: International Conference on Engineering Design, 1(1), pp. 309-318. https://doi.org/10.1017/dsi.2019.34

Self, J., Dalke, H. and Evans, M. (2009), 'Industrial design tools and design practice: An approach for understanding relationships between design tools and practice'. IASDR 2009 - Rigor and relevance idesign.

Thomas, D. R. (2006), 'A general inductive approach for analyzing qualitative evaluation data', American Journal of Evaluation, 27(2), pp. 237-246.

Zhang, W., Ranscombe, C., Radcliffe, D., \& Jackson, S. (2019). 'Creation of a Framework of Design Tool Characteristics to Support Evaluation and Selection of Visualisation Tools'. Proceedings of the Design Society: International Conference on Engineering Design, 1(1), pp. 1115-1124. https://doi.org/10.1017/dsi.2019.117 